\title{
Intestinal Neuroendocrine Neoplasm
}

National Cancer Institute

\section{Source}

National Cancer Institute. Intestinal Neuroendocrine Neoplasm. NCI Thesaurus. Code C5695.

A neoplasm with neuroendocrine differentiation that arises from the small or large intestine. It includes well differentiated neuroendocrine tumors (low and intermediate grade) and poorly differentiated neuroendocrine carcinomas (high grade). 